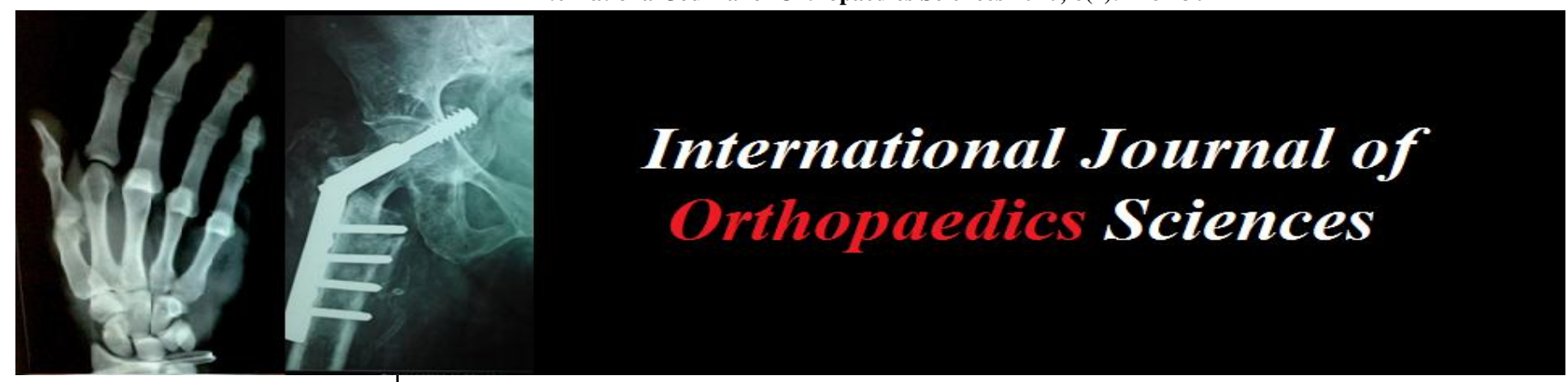

E-ISSN: 2395-1958

P-ISSN: 2706-6630

IJOS 2020; 6(4): 228-230

(C) $2020 \mathrm{IJOS}$

www.orthopaper.com

Received: 15-07-2020

Accepted: 18-08-2020

Dr. Raju Kulkarni,

Associate Professor, Department

of Orthopaedics, Mahadevappa

Rampure Medical College,

Kalaburagi, Karnataka, India

Dr. Vithal Gundappa,

Junior Resident, Department of Orthopaedics, Mahadevappa

Rampure Medical College,

Kalaburagi, Karnataka, India

\section{A short-term functional outcome of proximal diaphysio-metaphyseal fracture of tibia treated with intramedullary interlocking nail in combination with poller screw}

\author{
Dr. Raju Kulkarni and Dr. Vithal Gundappa
}

DOI: https://doi.org/10.22271/ortho.2020.v6.i4d.2345

\begin{abstract}
Non-articular fractures of the proximal third of the tibia account for 5 to $11 \%$ of tibial shaft injuries. Intramedullary nailing for metaphyseal tibial fractures with a shortproximal fragment (unlikediaphyseal tibial fractures) is associated with an increased risk of frontal and sagittalplane malalignment. This can be solved by the use of intramedullary interlocking nail in combination with blocking screws or Poller screws. A series of 20 cases of proximal diaphysis-metaphyseal fracture of tibia treated with intramedullary interlocking nail in combination with poller screw and were followed up regularly till 6 months and evaluated using Modified Karlstrom-Olerud Score. Most patients had Excellent score at $6^{\text {th }}$ month follow-up. Our study suggests intramedullary interlocking nail in combination with poller screwis an effective management of proximal diaphysio-metaphyseal fracture of tibia.
\end{abstract}

Keywords: Proximal diaphysio-metaphyseal fracture of tibia, Poller screws, blocking screws, intramedullary interlocking nail

\section{Introduction}

Proximal tibial fractures considered a more challenging injury. With the increasing number and the advent of high velocity transport system, there is an alarming increase in RTA with increased morbidity and mortality. Amongst every 10-15 trauma cases, there is one fracture shaft tibiaNon-articular fractures of the proximal third of the tibia account for 5 to $11 \%$ of tibial shaft injuries. The goals of treating these fractures are: achieving bony union, restoring soft tissue vitality, preventing infection and instituting early joint motion and muscle rehabilitation. A wide variety of nonsurgical and surgical methods of treatment are available. Intramedullary nail passes from one end of the bone to another end in the medullary canal, it acts as an internal splint. It allows the axial forces to be transmitted to the opposite end of the fragment. Intramedullary nailing for metaphyseal tibial fractures is associated with an increased risk of frontal and sagittal plane malalignment (procurvatum). This may be attributed to an inaccurate entry site or both displacing muscular forces and residual instability. The large difference between the size of the implant and the metaphyseal diameter increases the risk of malalignment. This can be solved by the use of blocking screws or Poller screws. Poller screws decrease the width of the medullary cavity, guide and block the nail in the centre of the widened metaphyseal area, and increase the mechanical stiffness of the bone implant construct. The aim of this study was to evaluate the functional outcome of Proximal diaphysiometaphyseal fracture of tibia with Intramedullary interlocking nailing and Poller screws.

\section{Materials \& Methods}

The study was conducted on 20 patientsabove 18years were enrolled after detailed clinical and appropriate radiological evaluation in Department of Orthopedics, Mahadevappa Rampure Medical College, Kalaburagi and other Private Hospitals in Kalaburagi. It was conducted between June 2018 to March 2020. Modified Karlstrom-Olerud Score was used to evaluate the functional outcome.
Corresponding Author: Dr. Raju Kulkarni, Associate Professor, Department of Orthopaedics, Mahadevappa Rampure Medical College, Kalaburagi, Karnataka, India 


\section{Inclusion criteria}

1. Age $>18$ yrs with clinically and radiologically diagnosed closed fractures of proximal diaphysio-metaphyseal tibia.

2. Type I, II and IIIA open fractures of proximal diaphysiometaphyseal tibia.

\section{Exclusion criteria}

1. Unstable communited fractures

2. Type III B and C open fractures of proximal diaphysiometaphyseal tibia

\section{Surgical Technique}

- Under Spinal Anesthesia, patient in supine position on a radiolucent table.

- $\quad$ The knee positioned in 90-degree flexion. A longitudinal incision about $4 \mathrm{~cm}$ was made from the inferior pole of the patella, patellar tendon was splitted in midline to expose proximal tibial ridge.

- The entry point of nail at articular ridge opened using a curved Awl.

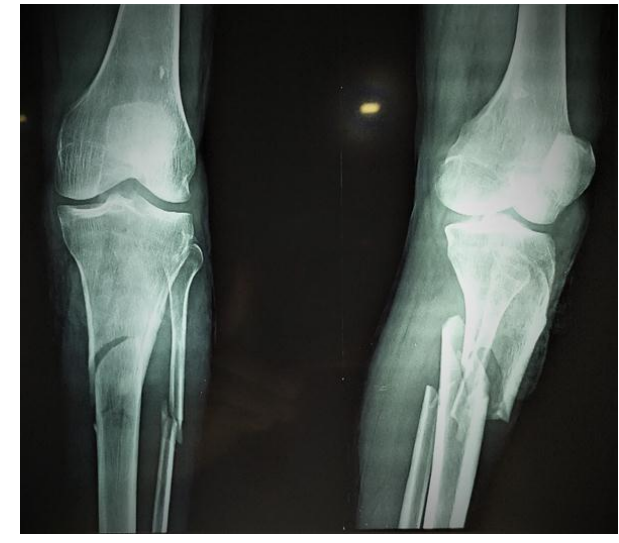

Fig 1: Pre-op X-ray

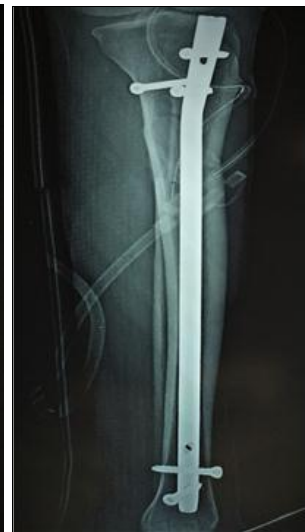

Fig 2: Immediate Post-op X-ray

- The fracture was manipulated manually or by using percutaneous clamp to achieve reduction.

- Poller screws were placed percutaneouslyatthe junction of posterior $2 / 3^{\text {rd }}$ and anterior $1 / 3^{\text {rd }}$ of tibia metaphysis above the Herzog bend or proximal to fracture medial to lateral direction

- Guide-wire passed through medullary canal down to level of the fracture site, then was directed toward the distal fragment and its position was checked again radiographically for further confirmation.

- The chosen nail attached to insertion jig and driven over the guide wire through the medullary canal

- Proximal and distal locking was done.

- Incision was closed in layers \& pressure dressing applied.

Physiotherapy protocol included Knee isometric exercises, Quadriceps strengthening exercises and Knee ROM exercises $\&$ non weight bearing for 6 weeks and weight-bearing was increased gradually, depending on the absence of pain and radiographic evidence of bone union.

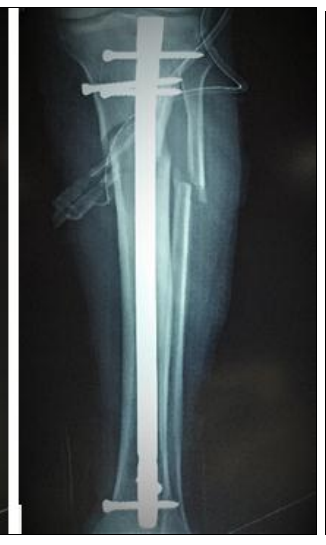

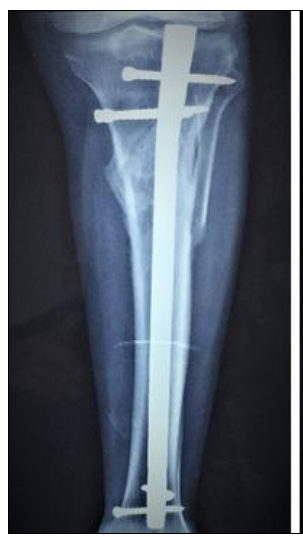

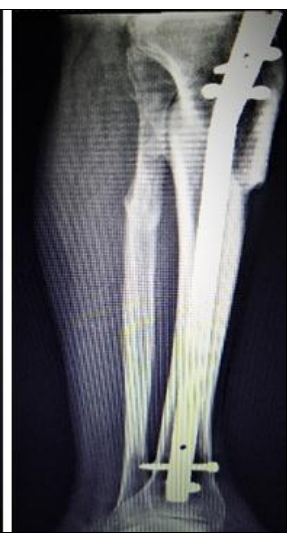

Fig 3: 6 months Post-op X-ray

\section{Results}

The patients were followed up postoperatively at 4 weeks, 3 months, 6 months. The results of the study had been evaluated through: union of fracture, ranges of motion of both knee and ankle joints, alignment of fracture, occurrence of infection, degree of knee pain, walking capacity, extension lag and stability of the knee joint. All cases had been united.

Table: Distribution of cases

\begin{tabular}{|c|c|c|}
\hline \multirow{2}{*}{ Parameter } & \multicolumn{2}{|c|}{ Total number of cases (20) } \\
\cline { 2 - 3 } & Number & Percentage \\
\hline \multicolumn{3}{|c|}{ Age Distribution (years) } \\
\hline $18-35$ & 5 & $25 \%$ \\
\hline $36-55$ & 10 & $50 \%$ \\
\hline$>55$ & 5 & $25 \%$ \\
\hline \multicolumn{3}{|c|}{ Sex distribution } \\
\hline Male Side Distribution \\
\hline Female & 16 & $80 \%$ \\
\hline Right & 2 & $20 \%$ \\
\hline Left & 18 \\
\hline \multicolumn{3}{|c|}{ Mode of Injury } \\
\hline Road Traffic Accidents & 18 & $10 \%$ \\
\hline Fall/Trauma & 2 & $90 \%$ \\
\hline
\end{tabular}

According to Modified Karlstrom-Olerud Score, out of 20 patients, 12 had excellent results, 5 had good results, 2 had satisfactory result $\& 1$ had poor result.

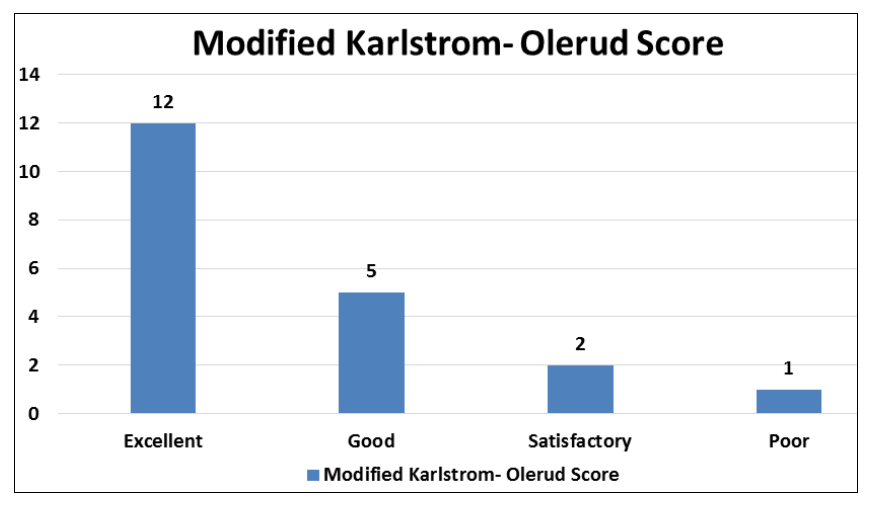

Fig 4: Final outcome

In our series, 1patient had delayed union, 2 patients had varus mal-alignment \& 2 patients developed superficial skin infection and treated with antibioticsNo case of implant failure developed.

\section{Discussion}

Controversy still remains regarding the use of IMN as a definitive management of proximal third tibial fractures. Historically, these injuries have been notoriously difficult to fix and maintain without early failure in some reported series. Malunion rates have been reported to be high and several earlier series offered high rates of fixation failure, typically into an apex anterior and valgus position.

The natural bony anatomy and muscular attachments of the 
proximal tibia offers the perfect set up for a number of common deformities after fracture with subsequent malalignment during IMN placement. These are due to muscular stresses via tendinous attachments. The dynamic forces of the patellar tendon pull the proximal fragment into an apex anterior angulation, whereas the attachment of the pes anserinus causes varus stress on the same fragment. These forces; in addition to the capacious medullary canal at this level, create the potential for improper reduction and suboptimal nail placement during nailing with conventional techniques for IMN of proximal third tibial fractures with the knee hyper flexed.

The use of Poller screws to supplement intramedullary nailing for metaphyseal proximal tibial fractures enable control of angular deformity and increases stability of fixation.

Poller screws act via a 3-point fixation principleto nullify the forces of muscle and ligament pull and narrow the metaphysis play. Additional Poller screws in the concave side can nullify tissue tension when they are placed close to the centre of rotation of angulation (CORA), adjacent to the nail track, and perpendicular to the deformity plane. Precautions should be taken not to apply the Poller screws away from the CORA or on the convex side.

The guidelines include: (1) taking a high entry point (if a low entrypoint is taken, a proximal Poller screw will have to beadded); (2) using a proper size high bend unreamed nail; (3) placing the nail co-axially with the long axis of tibia; (4) accounting for the nail bend distance; and (5) applying a second screw to avoid posterior translation. Poller screws are not just blocking screws but tools of reduction.

In a review by Freedman et al of 133 tibial fractures treated within tramedullary nails, proximal third fractures resulted in a significantly higher rate of tibialmalalignment than middle or distal third fractures. This was due to the lack of a sufficiently long posteriorcortex in the proximal fragment. A neutral to slightly lateral entrance angle for nail insertion should be used for proximal third tibial fractures.

\section{Conclusion}

We strongly recommend that the surgical management of open reduction/closed reduction with intra medullary interlocking nailing and poller screws in proximal tibial metaphyseal fractures -

- Is effective in achieving the fracture alignment with poller screw acting as a reduction tool.

- Gives improved stability of the bone - implant construct, with the poller screw functionally reducing the medullary width.

- Maintains the fracture alignment till union, preventing loss of initial reduction with poller blocking screw in situ.

\section{References}

1. Gustilo RB, Anderson JT. Prevention of infection in the treatment of one thousand and twenty-five open fractures of long bones retrospective and prospective analysis. J Bone Joint Surg Am. 1976; 58(4):453-458.

2. Lang GJ, Cohen BE, Bosse MJ, Kellam JF. Proximal third tibial shaft fractures. Should they be nailed? Clin OrthopRelat Res. 1995; 315:64-74.

3. Bono CM, Levine RG, Rao JP, Behrens FF. Nonarticular proximal tibia fractures: treatment options and decision making. J Am Acad Orthop Surg. 2001; 9(3):176-186.

4. Stedtfeld HW, Mittlmeier T, Landgraf P, Ewert A. The logic and clinical applications of blocking screws. J Bone Joint Surg. Am. 2004; 86(2):17-25.
5. Kulkarni SG, Varshneya A, Kulkarni S, Kulkarni GS, Kulkarni MG et al. Intramedullary nailing supplemented with Poller screws for proximal tibial fractures. J OrthopSurg (Hong Kong). 2012; 20(3):307-311.

6. Krettek C, Rudolf J, Schandelmaier P, Guy P, Konemann B, Tscherne H. Unreamedntramedullary nailing of femoral shaft fractures: operative technique and early clinical experience with the standard locking option. Injury. 1996; 27:233-54.

7. Krettek C, Miclau T, Schandelmaier P, Stephan C, Mohlmann U, Tscherne H. The mechanical effect of blocking screws ("Poller screws") in stabilizing tibia fractures with short proximal or distal fragments after insertion of small-diameter intramedullary nails. J Orthop Trauma. 1999; 13:550-3.

8. Insall JN. Surgery of the knee. New York: Churchill Livingstone, 1984.

9. Krettek C, Stephan C, Schandelmaier P, Richter M, Pape HC, Miclau T. The use of Poller screws as blocking screws instabilising tibial fractures treated with small diameter intramedullary nails. J Bone Joint Surg. Br. 1999; 81:963-8.

10. Ricci WM, O’Boyle M, Borrelli J, Bellabarba C, Sanders R. Fractures of proximal third of the tibial shaft treated within tramedullary nails and blocking screws. J Orthop Trauma. 2001; 15:264-70.

11. Stedtfeld HW, Mittlmeier T, Landgraf P, Ewert A. The logic and clinical applications of blocking screws. J Bone Joint Surg. Am. 2004; 86(2):17-25. 